\title{
Moving from a Product-Based Economy to a Service-Based Economy for a More Sustainable Future
}

\author{
Ioannis Bellos $^{* 1}$ and Mark Ferguson ${ }^{\dagger 2}$ \\ ${ }^{1}$ School of Business, George Mason University, Fairfax, VA 22030 \\ ${ }^{2}$ Moore School of Business, University of South Carolina, Columbia, SC 29208
}

June, 2015

*ibellos@gmu.edu

${ }^{\dagger}$ mark.ferguson@moore.sc.edu 


\section{Contents}

1 Introduction 3

2 From Products to Services 4

2.1 Leaving the "Product Comfort Zone" . . . . . . . . . . . . . . . . . . 4

2.2 The Strategy of Servicizing . . . . . . . . . . . . . . . 5

3 The Economic and Environmental Impact of Servicizing Models $\quad 8$

3.1 Servicizing: The "Triple-Threat Business Model?" . . . . . . . . . . . . . . 9

3.2 Assessing Business Model Performance against the Triple Bottom Line . . . 10

3.3 Servicizing: Possible Environmental Issues . . . . . . . . . . . . . . . . . . . 11

4 Implementing a Servicizing Strategy 12

4.1 Possible Transition and Implementation Challenges from Adopting Servicizing 12

4.2 From an Economy Based on Products to Services and Now, to Collaborative Consumption? . . . . . . . . . . . . . . . . . 16

4.3 Design Tools that can Facilitate Servicizing . . . . . . . . . . . . . 17

5 Conclusion $\quad 19$ 


\section{Introduction}

Traditionally, economic growth and prosperity have been linked with the availability, production and distribution of tangible goods as well as the ability of consumers to acquire such goods. Early evidence regarding this connection dates back to Adam Smith's Wealth of Nations (1776), in which any activity not resulting in the production of a tangible good is characterized as "unproductive of any value." Since then, this coupling of economic value and material production has been prevalent in both developed and developing economies throughout the world.

One unintended consequence of this coupling has been the exponential increase in the amount of solid waste being generated. The reason is that any production and consumption of material goods eventually generates the equivalent amount of (or even more) waste. Exacerbating this problem is the fact that, with today's manufacturing and supply chain management technologies, it has become cheaper to dispose and replace most products rather than to repair and reuse them. This has given rise to what some call a "disposable society."

To put things in perspective: In 2012 households in the U.K. generated approximately 22 thousand tons of waste, which amounted to $411 \mathrm{~kg}$ of waste generated per person (Department for Environment, Food \& Rural Affairs, 2015). During the same time period, households in the U.S. generated 251 million tons of waste, which is equivalent to a person generating approximately $2 \mathrm{~kg}$ of waste every day (U.S. Environmental Protection Agency, 2012). Out of these 251 million tons of total waste generated, approximately $20 \%$ of the discarded items were categorized as durable goods. The disposal of durable goods is particularly worrisome because they are typically produced using material from nonrenewable resources such as iron, minerals, and petroleum-based raw materials.

It is clear that any business model that relies on a disposable society cannot be sustainable long-term model. For this reason, recent efforts have been made by policy makers to enable the creation of a "circular economy," which minimizes waste by re-using, repairing, refurbishing, and recycling materials and products (European Commission, 2014). While doing so can minimize the amount of waste produced and promote a more efficient and ecofriendly use of overall resources, the creation of a circular economy does not really address the source of the problem-it is consumption that is the source of most wastes. Thus, reducing consumption can result in decreased production and less waste.

One solution to the disposable-society problem, proposed by the U.S. Environmental 
Protection Agency's Office of Resource Conservation and Recovery (U.S. Environmental Protection Agency, 2009), is for traditional product-based firms to move towards more service-based business models that do not focus on selling products but rather on selling the solutions that the products can deliver. A potential benefit of such models is that a firm can always maintain the ownership of the products it manufactures, thus reducing the incentive to increase revenue by simply selling more products. Moreover, switching the base of the transaction, from the product level to the use level, can restructure the economics of consumption and encourage more sustainable level of product use. In this chapter we examine the potential of such a solution from both an economic and environmental perspective.

The rest of this chapter is organized as follows. In Section 2 we first provide examples of firms that have transitioned from a product-based state to a service-based state and then we introduce the concept of servicizing. In Section 3 we discuss some reasons why traditional product-based firms may be interested in transitioning to a more service-based delivery strategy and how this transition may impact a firm's sustainability metrics. In Section 4 we discuss some of the challenges firms may face when making this transition and some of the key decisions that are required for doing so. We conclude in Section 5 and provide some possible directions for future research.

\section{From Products to Services}

In this section we describe how certain companies have made the transition from being product-based to being service-based. We also link such a transition to what has recently become known as servicizing strategies.

\subsection{Leaving the "Product Comfort Zone"}

The service sector has been an integral part of economic activity in both developed and developing economies. In 2013 services accounted for approximately 80\% of GDP in the U.S. (The World Bank, 2013). During the same period, in China the service sector continued to grow to $46.9 \%$ of GDP, a dynamic that may indicate the move to a new stage in China's economic growth (Businessweek, 2014).

Although such statistics are commonly used in texts describing the role of services in today's economy, another observation may help put a more interesting "face" on these 
numbers. In particular, for many years organizations that are (or were) typically recognized as manufacturing/product firms have been increasing the service component of their offerings. Examples include GM's successful creation of the OnStar subscription service or its expansion to financial services through the acquisition of AmeriCredit Corp. in 2010 to create what is known today as GM Financial. Similarly, SKF, the Swedish manufacturer of ball and roller bearings, now offers subscription-based diagnostic and predictive maintenance services (SKF, 2014). Dell and Hewlett-Packard created Dell Services and HP Enterprise Services, respectively, in order to provide IT and business services. These moves came in response to earlier moves by IBM, who has almost entirely transformed itself from a product-based company into a services company by selling its personal computers and servers business to Lenovo (Lenovo, 2004; IBM, 2014).

But why do manufacturers choose to go out of their "product comfort zone" to engage and invest in the creation of services? In the face of product commoditization and increasing competitive pressure, services can offer a stable and recurring revenue stream stemming from activities such as support, maintenance, and repair, which can extend well beyond the useful life of a product and generate lucrative profit margins. This can also increase the chances of cross-selling or alleviate customers' hesitation in upgrading to new products and equipment. Additionally, by offering after-sales support services, manufacturers can eliminate the need for third parties, who can erode brand perception, to perform these services. Furthermore, services are more difficult to reverse-engineer (i.e., to be imitated) and can facilitate longer and deeper relationships with customers due to longer contractual agreements. Manufacturers can also obtain a better idea about the customers' needs and the conditions under which the products operate and possibly customize their offerings accordingly. Finally, by offering services the manufacturers can acquire more accurate feedback about the performance of their products in the field, which can lead to product improvements and redesigns.

\subsection{The Strategy of Servicizing}

In the aforementioned examples, regardless of whether the manufacturers offer a support (e.g., maintenance) or an "add-on" (e.g., OnStar) service, the base of the transaction remains at the product level. This is because the service is contingent on the customers purchasing a product. However, in recent years we have observed a trend where manufacturers from various industries have started switching their focus from selling products to 
actually selling the solutions that their products offer. In most of the cases, manufacturers maintain the ownership of the products; therefore, the base of the transaction no longer seems to be the product per se, but rather the use of the product. This trend, also known as "servicizing, ${ }^{1}$ " indicates the transition from a product-based economy to a functional or solutions economy (Stahel, 1994). In such an economy, instead of buying chemicals, for example, customers now have to option to buy chemical management services; instead of buying copiers, they can buy document reproduction services; and instead of buying cars, they can buy mobility services (see Figure 1). Such options can be particularly attractive to customers because they free them from the administrative hassles and the operating risks (e.g., maintenance, repair) as well as the financial risks (e.g., depreciation of a product's market value) associated with product ownership.

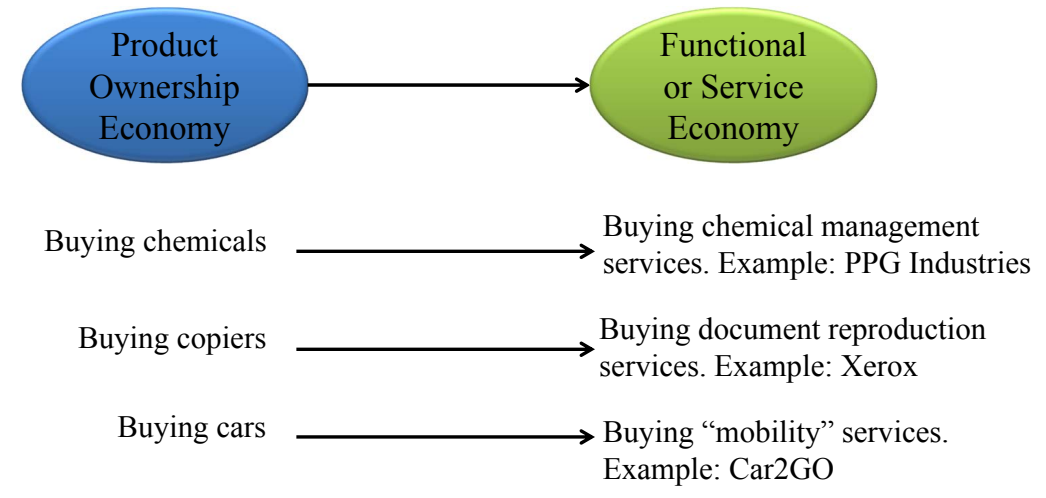

Figure 1: The transition from a product-ownership economy to a functional economy (adapted from White et al., 1999).

The strategy of servicizing involves the transition from an existing business model to one where the focus is on the service or, better put, the solution provided to the endcustomer. In fact, most business models can be thought of as comprising a combination of a product and a service component (see Figure 2). A newly formed definition in the academic literature describes these models under the general term Product Service Systems (PSS). The definition of PSS varies throughout the literature but most authors agree that there exist three different PSS types (U.S. Environmental Protection Agency, 2009): i) productoriented PSS in which a manufacturer, in addition to selling a product, includes extra

\footnotetext{
${ }^{1}$ There is an abundance of similar terms like "servicization" or "servitization." We have chosen to use the term "servicizing" like many before us, without making any claims about its superiority or grammatical correctness!
} 
services (e.g., after-sales service), ii) use-oriented PSS in which the manufacturer maintains ownership of the product and sells the use or availability of it (e.g., leasing, rentals, car sharing), and iii) result-oriented PSS in which the manufacturer and the customer agree on a certain result or performance level (e.g., engine up-time).

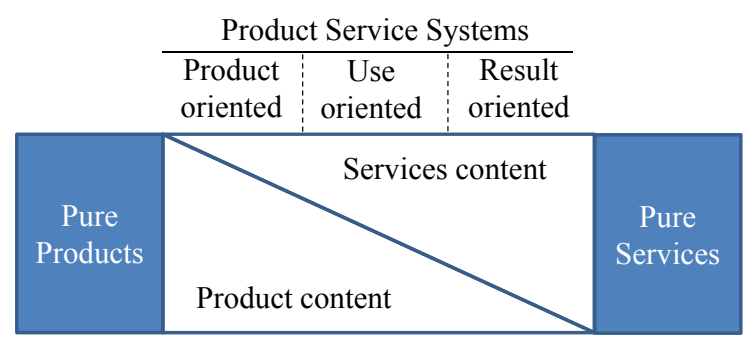

Figure 2: Product-Services spectrum and the different types of Product Service Systems (adapted from Tukker, 2004).

The above typology is by no means exhaustive, and some business models may fall under more than one type. For instance, the business model of fractional ownership (often found in the private jet industry; NetJets was among the first to offer such a model) where customers own only a fraction of an asset that entitles them to a certain amount of use, can be thought of as a combination of product-oriented and use-oriented PSS. In this chapter we avoid possible categorization conundrums and simply describe models in which the use, rather than the ownership, of the products governs the relationship between manufacturers and customers. To avoid an overly cumbersome use of terminology and unnecessary confusion, we refer to such models as servicizing business models.

One of the most celebrated examples of a successful servicizing business model in the academic literature is Xerox's document management services (Xerox, 2014), where customers are charged on a per-use (per-page-printed) basis (see Fischer et al., 2012). In the automotive sector, servicizing has emerged through the business model of car sharing. Under car sharing, customers obtain access to a fleet of vehicles after paying a small annual fee. Upon joining the service, customers can check the availability of the vehicles and make reservations online. After using a vehicle, they pay only for the reserved amount of time. Although the most Although the most well-known car sharing provider is Zipcar, several auto manufacturers such as BMW, Peugeot, and Ford have entered the car sharing arena through small, pilot programs across the world. The most prominent and fastest-growing car sharing program offered by an auto manufacturer is Car2Go, a subsidiary of Daimler 
AG, which operates in several cities across the U.S. and Europe.

An example of a servicizing model in the aviation sector is offered by Rolls-Royce, who pioneered Power-by-the-Hour maintenance agreements under which it charges customers based only on the actual flying hours of the engines. ${ }^{2}$ For more examples of servicizing business models, we refer the reader to Rothenberg (2007), U.S. Environmental Protection Agency (2009), and Fischer et al. (2012).

Researchers have argued that servicizing business models can lead to higher profitability. In particular, they have proposed that by focusing on the final customer needs and delivering integrated solutions fulfilling these needs companies can improve their positions in the value chain, enhance the value of their offerings, and improve their innovation potentials (Wise and Baumgartner, 1999; Sawhney et al., 2003). Such arguments are in line with our previous mention of the economic benefits of more service-oriented business practices. Besides the potential economic benefits that more service-oriented business models may hold, recently researchers and environmental groups have argued that servicizing business models may also be associated with environmental benefits and, therefore, can be positioned to support the objective of sustainable development (Rothenberg, 2007). Throughout the rest of this chapter, we explore some of the rationale for this claim.

In this section we formally introduced the concept of servicizing and presented some of its most successful implementations in practice. We concluded by mentioning the support that servicizing has received as a potentially win-win (i.e., economically and environmentally superior) business strategy. In the next section we further explore some of the arguments regarding the economic and environmental potential of servicizing business models.

\section{The Economic and Environmental Impact of Servicizing Models}

In this section, we provide details regarding the economic and environmental appeal of servicizing models and, more specifically, their potential to support the three pillars of sustainability: people, profit and planet.

\footnotetext{
${ }^{2}$ The term performance-based contracting is also used to describe agreements that are similar in spirit.
} 


\subsection{Servicizing: The "Triple-Threat Business Model?"}

The decoupling of customer value from product ownership seems to be at the heart of the arguments in support of the environmental potential of servicizing. The reason is that this decoupling can contribute to the dematerialization of the economy (Heiskanen and Jalas, 2000) by requiring less energy or material to generate the same (or even more) customer value. This can sometimes be achieved simply through using novel contractual mechanisms. For instance, in the context of chemical management solutions, shared-savings contracts are sometimes used between suppliers and buyers instead of the typical price-quantity contracts. Under such contracts, a supplier is not rewarded based on the material sold to the buyer but, rather, based on the savings that the buyer enjoys due to a reduction in the consumption of such materials (Corbett and DeCroix, 2001; Corbett et al., 2005).

For another context in which dematerialization may also occur, consider the business model of car sharing. By the very nature of this model, car sharing providers like Car2Go can benefit from a pooling effect and satisfy customers' needs through a smaller number of vehicles because a single vehicle can be used by many customers at different periods of time. This results in better fleet utilization and overall lower production volume, which directly benefits the environment by reducing the production-related emissions and use of raw material. This is true under several servicizing models, the providers of which do not need to dedicate one product to each customer.

The arguments for the environmental superiority of servicizing are also supported by the fact that, in the majority of the business models, customers are charged on a per-use basis (e.g., per-page-printed, per-mile-driven etc.). Directly linking payment to product usage may incentivize customers to reduce their use of the product, resulting in a lower environment burden. The decrease in usage due to pay-per-use pricing is attributed to what is known as the taxi-meter effect (or flat rate bias; see Lambrecht and Skiera, 2006), which postulates that customers enjoy their product usage more at a flat rate and tend to use it less when they are charged for each unit of usage.

Finally, in most of the servicizing business models the manufacturer maintains the ownership of the products. This may incentivize manufacturers to design and produce products of higher reliability (Guajardo et al., 2012) or with longer useful life, so as to maximize the revenue extracted from each product per unit of time. This can also be achieved through better maintenance, which can typically be accomplished more productively by the manufacturer than the customer. Such practices also affect the end-of-life management of the 
products since a manufacturer is more likely to choose a more environmentally friendly way to dispose of a product than a customer and may even reduce the number of units that are disposed of in any given period of time by prolonging the useful lifecycles through remanufacturing or harvesting spare parts.

Do the above-mentioned arguments imply that servicizing is the "triple-threat business model," that is, a business model that excels simultaneously in all three pillars of sustainability: people, profit, and planet? Recent research (Bellos et al., 2013; Agrawal and Bellos, 2015) shows that this may not always be the case. But why not? Before we answer this question, we need to understand how the three pillars of sustainability relate to each other and how the performance of a business model with respect to these dimensions is assessed.

\subsection{Assessing Business Model Performance against the Triple Bottom Line}

With respect to the profit dimension, it is straightforward to argue that, for a given (payper-use) price, profit increases as the number of customers who use the firm's products increases and/or the amount of use that each customer extracts from the product increases (i.e., as customers drive more or print more pages).

With respect to the people dimension, one way to estimate the impact of a new business model is to measure the overall consumer surplus. Assuming that every customer derives a positive utility from using a product, then for a given (pay-per-use) price higher product usage increases an individual consumer's surplus. Similarly, the overall consumer surplus increases as the number of customers who adopt and use a product increases.

This brings us to the third dimension: that of environmental performance (i.e., the planet). To assess the environmental performance of a business model, a lifecycle approach can be adopted and the environmental burden created at the phases of production, use, and disposal can be calculated (Agrawal et al., 2012). The environmental burden during the production and disposal phases depends on the total number of products manufactured and disposed of during each time period, while during the use phase it depends on the amount of the overall use that customers extract from the products (it may already be apparent that what increases profit or consumer surplus may also increase the environmental burden). Each phase may also be characterized by a different per-unit environmental impact. For instance, a certain type of product may cause a higher environmental burden during the 
use phase as opposed to the production or disposal phase.

\subsection{Servicizing: Possible Environmental Issues}

From an environmental point of view, the implementation of servicizing, as opposed to a traditional sales-only business model, can backfire from a few angles. As an example, consider again the business model of car sharing. It is true that customers may choose to relinquish car ownership and decide to cover their transportation needs by joining a car sharing program, something that would constitute an environmental win. However, at the same time, car sharing may make car usage more attractive to customers who typically use more sustainable modes of transportation (e.g., biking and/or public transportation). While the pooling effect may cause the overall number of vehicles produced to decrease, a larger number of customers adopting car sharing may imply that the overall level of vehicle usage increases (see Bellos et al., 2013). Despite the fact that such an increase in usage may lead to a higher profit and higher consumer surplus, it can also be environmentally problematic because several studies (Sullivan and Cobas-Flores, 2001; MacLean and Lave, 2003) have shown that the majority of the environmental impact of an automobile occurs during the use phase of its lifecycle. This issue may not be unique to car sharing, as many other types of products are characterized by higher use rather than production impact.

Even the pooling effect, which can be directly linked to the concept of dematerialization, may also be responsible for some unintended environmental drawbacks. The reason is that a smaller production volume due to pooling results in a smaller overall production cost, which may allow the manufacturer to: i) lower the prices and/or ii) invest in improving the product efficiency (the manufacturer may be particularly interested in improving product efficiency because under most servicizing business models the manufacturer is responsible for the operating cost of the product). Since lower prices and improved efficiencies may further increase adoption and overall product usage (and therefore profitability), the wellknown Jevons paradox ${ }^{3}$ may occur and result in higher environmental burden.

In this section we provided a brief summary of the economic and environmental implications associated with the implementation of a servicizing business model. For an analysis of the environmental performance of servicizing, we refer the reader to Agrawal and Bellos (2015). In what follows, we provide more details on how firms may implement a servicizing

\footnotetext{
${ }^{3}$ According to the Jevons paradox (also referred to as the rebound effect; Greening et al., 2000), the overall rate of consumption of a resource increases as the efficiency of the resource improves. That is, as we make the usage of something cheaper, we tend to use more of it.
} 
strategy and some of the major challenges inherent in doing so.

\section{Implementing a Servicizing Strategy}

Having discussed some of the multiple benefits that a servicizing strategy can provide, we now outline some of the possible implementation challenges that an organization may face during the transformation of its business model from a product-based one to a solutionsbased one. In addition, we describe the close relationship of an even newer class of business models, known as collaborative consumption models, to servicizing business models. Finally, we provide information about a design technique that is widely used in practice and which can facilitate the implementation of a servicizing strategy.

\subsection{Possible Transition and Implementation Challenges from Adopting Servicizing}

From an economic point of view, the transition to services has not always been successful, as there have been several cases where increasing the service component of a product-based organization decreased the overall firm performance (Gebauer et al., 2005). Interestingly, recent research (Suarez et al., 2013) has identified a non-linear effect between firm profitability and the extent of the service involvement. Specifically, services appear to have a positive effect on profitability after they reach a critical point of contribution to the firm's overall revenue. This may indicate a strategy where firms initially provide their services at a low price in order to attract customers into buying their products. As the number of customers reaches a critical mass, the firms may tend to focus on service delivery and to streamline the relevant processes, resulting in improved profitability.

One may argue that the inability of some product organizations to reap the benefits of providing services relates to the hurdles they face trying to transition from a product-based mentality to a service-based one. These hurdles can be attributed to the inherent differences ${ }^{4}$ between managing products and managing services. For instance, in product-based environments, centralization, efficiency, economies of scale, and standardization share a common underpinning, that of eliminating variability, which is almost always considered

\footnotetext{
${ }^{4}$ Some of these differences are probably hard-coded due to differences in the training of key stakeholders. Such differences typically fortify silos within organizations. For instance, think of the eternal clash of the "hard" engineering/operations with the "soft" marketing side of the house.
} 
to be a necessary condition for successful operational and financial performance. Now compare this with the unique characteristics (Zeithaml et al., 1985) that services are known to hold: i) intangibility (i.e., lack of specifications), ii) heterogeneity in the customer requests and/or the service outcome, iii) perishability (i.e., inability to inventory service performance/outcome), and iv) co-production (i.e., the need for both the provider and the customer to be engaged to deliver the service outcome). If anything, these characteristics imply an exposure to higher variability. Therefore, the tension between the two worlds immediately becomes apparent. Moving from one mindset to another may arguably require extensive organizational "rewiring."

Certain implementation challenges, however, may be unique to (or at least more pronounced under) a servicizing business model that attempts to decouple product ownership from customer value. Such challenges may pertain to:

- Internal resistance from employees, especially salespeople, who under a product regime are typically compensated based on commissions tied to the quantity of products or material sold. Under servicizing, the base of the transaction is the solution that the product offers, not the product per se. For this reason, incentive mechanisms will have to be redesigned so they do not depend on the quantity of products sold. New incentives may be focused on customer retention, increases in revenue, expansion of the customer base, etc. This can be a rocky transition because the differences in the magnitude of the dollar amount per transaction can be vast. For instance, $60-70 \%$ of the maintenance cost of a jet engine is attributed to the cost of materials. Replaceable parts include airfoils, blades, and guide vanes. A turbine blade may cost as much as $\$ 8,000$. Given that an engine may comprise 60 to 80 blades, this can bring the value of a potential sale up to $\$ 700,000$ for the maintenance of a single engine (information and numbers based on Ackert, 2011). Without proactively addressing the compensation schemes, a company may realize a loss of talent during the early stages of the transition to servicizing. Toffel (2008) provides a thorough discussion on the agency issues in servicizing business models.

- The complexity of the new contractual agreements. This can be the case especially when such agreements are based on (uncertain) product performance (e.g., engine up-time). The cost of implementing such contracts may be more difficult to estimate since it depends on performance that is unrealized at the time of the agreement. Because of this, manufacturers may be tempted to overpromise on key performance 
metrics. However, failure to deliver on these promises may impose steep penalties, either by financially compensating the customer or by making last minute arrangements (e.g., through third-party providers) to ensure that customer needs are met. Of course, such problems may subside over time due to the manufacturer obtaining better data about the performance of the products or the client's operating needs and conditions. The manufacturer may even use this feedback to invest in products with higher reliability (Guajardo et al., 2012).

Changing the base of the transaction from the product to the service and solution level can be challenging for the customers too. The reason is that such a change also affects the basis of the cost-benefit analysis. Assessing the benefit requires a good estimation of the product usage needs (e.g., how many pages we print per year and what we gain from that), whereas assessing the cost requires the holistic estimation of expenses related to functions such as purchasing, operation, maintenance, and disposal, which for most organizations are decentralized (i.e., different parts of the organization are responsible for each function).

For instance, consider the failed attempt of Interface to transition from selling carpets to offering "floorcovering services." Specifically, through what was known as Evergreen $^{\mathrm{TM}}$ Services Agreement (EVA), instead of selling carpets, Interface began offering long-term carpet leases that required the purchase of additional support services such maintenance and selective tiles replacement. However, several years after launch and despite the strong support from top-management, the EVA's market acceptance remained weak. One of the main reasons was that customers rarely understood how much they currently were spending on cleaning and maintaining their carpets since these expenses were often buried under more general maintenance and cleaning budgets. For this reason, the EVA option often appeared to be uneconomical compared with the perceived status quo (Oliva and Quinn, 2003; for a more detailed discussion of the reasons EVA failed, see Toktay et al., 2006, and Ferguson and Plambeck, 2008).

- Behavioral effects such as the endowment effect, which postulates that customers tend to place more value on objects that they own than on those that they do not (Thaler, 1980; Kahneman et al., 1991) and, for that reason, may not find servicizing as appealing as direct ownership. Although there is already evidence (The Economist, 2012) that customers (especially of younger age) now exhibit a more utilitarian atti- 
tude towards consumption that is not influenced as much by behavioral effects, this is a cultural/generational change that may require time to fully occur. Also, the lack of product ownership may induce availability or accessibility anxieties, similar to the range of anxieties observed among drivers of electric vehicles (Avci et al., 2015; Lim et al., 2015).

- Faster deterioration due to heavier use or more frequent repairs of the products due to customers' careless use, or even abuse, of the equipment. For instance, car-sharing customers may be less mindful of road hazards or may be less conservative with their driving behavior when they are not financially responsible for the maintenance of the vehicle they use. Such behavior can also diminish possible environmental benefits because it may either decrease the efficiency of the products (i.e., products may require more energy to deliver the same amount of use) and/or may require the provider to replace the products more often (i.e., it may increase the number of products required per unit of time). As another example, theft, damages, and vandalism are among the most challenging problems that Vélib, the French bikesharing provider, has been facing since it started operating in Paris in 2007 (The New York Times, 2009; France24, 2013). Extra security measures, monitoring mechanisms, product redesigns, and more frequent maintenance, however, can partially address such issues, albeit at an increased cost.

- Customer-induced negative externalities. Specifically, the fact that under servicizing customers do not maintain product ownership implies a loss of control over the product and that the value each customer derives, to a certain extent, depends on decisions made and actions taken (even inadvertently) by other customers. For instance, in a car sharing model, a late return of a vehicle can interfere with the reservations of other customers. Similarly, failure of one customer to refuel or maintain a vehicle's cleanliness can negatively affect the experience of the other users. To counter such negative experiences, the provider may be required to install monitoring mechanisms along with a penalty structure to dissuade such behaviors. However, such "instrumental controls" (Frei, 2005) may be perceived as a license to break the rules (e.g., license to be late in the case of car sharing) because it quantifies the implications of doing so and, therefore, a customer can engage in a cost-benefit analysis, ignoring how their actions will affect other customers. According to Levitt and Dubner (2005), this was the case when some daycare centers in Israel imposed penalties on 
parents who were late in picking-up their kids. After announcing the fees the centers observed an increase in the parents' tardiness (the original experiment can be found in Gneezy and Rustichini, 2000). On the contrary, "normative controls" rely on subjective measures such as shame, guilt, embarrassment, and a sense of community or sense of duty. A provider's task is thus to devise mechanisms that can deter unacceptable behavior by eliciting such reactions and feelings. For instance, Zipcar always tries to create a sense of community by referring to its members as "Zipsters" or by featuring stories of its members and employees on its online magazine Ziptopia. For an excellent discussion of instrumental versus normative controls, see Frei (2005).

\subsection{From an Economy Based on Products to Services and Now, to Col- laborative Consumption?}

Recently, a new type of business model has been gaining traction by building on what is known as collaborative consumption. The concept of collaborative consumption refers to the type of consumption that takes place through (peer-to-peer) sharing, swapping, lending, or other similar activities (Botsman and Rogers, 2011). Such activities may or may not involve monetary exchange. For instance, other than maybe some gestures of appreciation (e.g., cooking dinner), members of Couchsurfing do not typically exchange money in return for the hospitality provided. On the other hand, in the more well-known business models of Airbnb and Uber, participating members (i.e., qualified hosts and drivers) contribute their properties by listing their apartments/houses and driving services, respectively, to the greater pool in return for monetary compensation, which is typically based on the amount of time the property was used by other customers. Similar to servicizing, ${ }^{5}$ the importance of product ownership is diminished in the sense that no ownership rights are transferred to each end-user and payment is linked to product usage.

Business models that rely on collaborative consumption may alleviate some of the economic issues identified earlier for the servicizing models by achieving a middle ground. For instance, drivers of Uber can still maintain the pride of ownership of their vehicles and, at the same time, improve the utilization for a fair compensation. Essentially, such

\footnotetext{
${ }^{5}$ It has been suggested that PSS can be thought of as a special category of collaborative consumption business model (Botsman and Rogers, 2011). However, we should point out that most collaborative consumption models are found in $\mathrm{B} 2 \mathrm{C}$ contexts and are typically offered by third-party providers. In contrast, servicizing models are observed in both $\mathrm{B} 2 \mathrm{C}$ and $\mathrm{B} 2 \mathrm{~B}$ settings and often are offered by manufacturers and/or third party providers.
} 
models achieve a more efficient matching of supply with demand by: i) increasing both the availability and accessibility of capacity, ii) encouraging efficient allocation of the supply through centralized and dynamic pricing, and iii) removing information asymmetries regarding the quality of the product/service through online review systems.

From an environmental point of view, however, it is not clear whether such new business models will have a positive impact. For instance, one may argue that Uber may be actually contributing to a higher environmental burden because, to a certain extent, it makes vehicle ownership more affordable by creating another source of revenue through which drivers can cover car ownership-related expenses (i.e., gas, maintenance, insurance, etc.). On the other hand, it can also be argued that it contributes to creating a more developed and interconnected network of transportation. As an example, it may make it easier for a traveler to hire an Uber cab to head to a Metro station and then use public transportation to travel to the final destination (e.g., the airport). Therefore, there may be segments of the market that find it more economical to cover their transportation needs through Uber (and public transportation) and, for that reason, choose to relinquish car ownership, thus contributing to the dematerialization of the economy.

Future research is needed to shed more light on the economic and environmental implications of collaborative consumption models. One promising direction can be the identification of the profile of customers (e.g., in terms of income or usage needs etc.) who would benefit most from choosing to cover their needs through such models.

\subsection{Design Tools that can Facilitate Servicizing}

Implementing a servicizing strategy to transform from a product organization to a solutions organization will probably come along with an array of critical decisions. For instance, the firm may need to determine: the pricing structure (e.g., how much to charge and whether to include a fixed fee in addition to a pay-per-use fee), the capacity (e.g., in the context of car sharing, the size of the fleet; see Bellos et al., 2013), the efficiency/reliability/durability of its products (see Guajardo et al., 2012 and Agrawal and Bellos, 2015) or to what extent (if any at all) the "business-as-usual" model of selling products should be abandoned (e.g., the firm may decide to focus entirely on selling products, offering solutions or offering both solutions and selling products; see Agrawal and Bellos, 2015).

However, before a firm starts tackling such issues, certain aspects of which it may have addressed in its existing business model (e.g., pricing issues are not unique to servicizing 
business models), it is important to identify the key differentiator between the practice of selling products and the practice of selling solutions. To do so it could attempt to answer the question of whether moving from the product business to the solutions business requires a materially different perspective. Namely, does the firm need to use different lenses to look at its offerings, or does it suffice to focus on the aforementioned operational and marketing issues (e.g., determining the capacity and the pricing, respectively)?

To answer these questions requires going through the task of rephrasing and reframing everything in terms of solutions. This can be a revealing exercise. For instance, thinking in terms of selling mobility solutions (as opposed to selling cars) may uncover that the order winners no longer have to do with certain product specifications (e.g., time to increase speed from 0-60 mph) and features (e.g., whether a specific car model comes with dual climate control and electronically adjustable seats). This first step can eliminate the productrelated tunnel vision and enable the firm to start thinking along the lines of how to best assist their customers in meeting their basic needs.

This implies a holistic perspective that extends before and after the transaction point (i.e., the point where payment occurs) between a customer and a firm. For instance, the satisfaction that customers derive from meeting their mobility needs through a car sharing program is also determined by the ease with which they: navigate through the website to find available vehicles and make reservations, make changes in their reservations, find the designated parking lot and the reserved car, address unforeseen situations (e.g., having a flat tire), and, finally, make payments and manage their accounts. The challenge in this case for the firm is to identify the different elements that shape the overall customer experience.

Towards this end, design thinking can be of great value. Design thinking (Brown, 2008) refers to a human-centered design approach that relies on direct observation and rapid prototyping (indeed, services can be prototyped; see Thomke, 2003) to create solutions that holistically address customer needs. It goes beyond traditional marketing techniques (e.g., focus groups) because it allows customers to be in their natural environment where they may use a product or receive a service. This is typically achieved through empathic techniques (Leonard and Rayport, 1997) such as shadowing, which allow researchers to have a customer-centric view of the firm's offering. One of the most insightful and practical outcomes of these techniques is the creation of the customer journey map ${ }^{6}$. The customer

\footnotetext{
${ }^{6}$ The concept of the customer journey relates to the service blueprints first mentioned in the seminal work of Shostack (1987). For a more recent discussion on the application of service blueprint see Bitner et al.
} 
journey map delineates the series of different steps/stages that customers go through every time they satisfy a need (e.g., mobility need). These different stages are known as touchpoints (or moments of truth; see Bitner et al., 2008) because they indicate points/moments at which customers possibly interact with some aspect of the firm's offering (e.g., interact with the online reservation system) and derive an experience.

The value of the customer journey rests on the fact that it enables the firm to identify all the different elements that positively contribute to the customer experience along with the points of failure in which the firm needs to improve on. Essentially, it delineates the process through which customers interact with the firms. This process-based view is indicative of the role that the operations management discipline can play in the development of such methods. In addition to the process, the people (i.e., user) dimension is in support of the expansion of the celebrated " $4 \mathrm{P}$ 's" of the marketing mix to " $6 \mathrm{P}$ 's" that define the service mix (Teboul, 2006). The customer journey represents a method that is conducive to collaborations among disciplines that can break the silos we mentioned before. IDEO, the innovation and design consulting firm, has pioneered its use as a design method in the domain of both products and services (Bhavnani and Sosa, 2006) through the use of diverse and interdisciplinary teams. For an analytical treatment and discussion on the use of the customer journey as a service design framework, we refer the reader to Bellos and Kavadias (2014).

Admittedly, we have presented two sides of the same coin. On one side, the transition to servicizing can be a challenging one as there are many difficulties that an organization may have to tackle. On the other (brighter) side, there are multiple benefits such as a growing demand for innovative business models that depart from conventional product/ownershipbased models and the existence of established design methods that can be used to make the implementation of servicizing models easier. In the next section, we conclude this chapter by offering some thoughts on what remains to be done.

\section{Conclusion}

The increasing number of manufacturing companies that transition to more service- and solution-oriented business models indicates that Theodore Levitt's quote that "People don't want to buy a quarter-inch drill. They want a quarter-inch hole!" (Christensen et al., 2006)

(2008). Stickdorn and Schneider (2010) describe additional design thinking methods applied on services. 
is more true and relevant than ever. Done correctly, this transition will be associated with environmental as well as economic benefits. In this chapter, we explored some potential advantages and disadvantages, from both the economic and environmental perspective, associated with this transition. Identifying these advantages and disadvantages is an important step closer to a service-based economy. However, there is more work that needs to be done both from researchers and practitioners to help overcome the hurdles that firms may face when making this transition. For instance,

- From an academic/research point of view: existing assessment methodologies such as Lifecycle Analysis (LCA) may have to be further developed and applied in servicizing settings to account for usage patterns, which may differ significantly compared with when customers own the product. Along these lines, it is not clear whether offering certain types of products through servicizing may result in more frequent replacement (due to increased wear and tear) and overall larger production quantity than other types of products. Furthermore, more light needs to be shed on the major drivers that determine customers' decisions to forego product ownership. When is the lack of ownership more acceptable to customers, and what kind of technologies need to be developed to alleviate "anxieties" about product unavailability (i.e., the concern about not having access to a product when needed)? Can offering an increased variety of products (e.g., under a car sharing program this would imply offering an increased variety of brands and trims) make servicizing models more appealing as customers get to experience a broader range of products?

- From a managerial point of view: perhaps the greatest challenge is a cultural one. Manufacturers need to realize that they are in the solutions business and act on this realization. Ford has already started its transition to a "mobility company" (Fortune, 2015) and hopefully more manufacturers will be encouraged to follow this example. Of course, such a transition cannot and should not happen overnight. As highlighted by several successful cases (Ford, 2015; Peugeot, 2015), constant experimentation through small-scale pilot programs is likely the safest approach that manufacturers can use to gain momentum and make the transition.

Overall, we hope that our discussion in this chapter will motivate further interest in the exciting topic of servicizing as an alternative business model for product-centric firms. 


\section{References}

Ackert, S. 2011. Engine Maintenance Concepts for Financiers. Elements of Turbofan Shop Maintenance Costs. http://www.aircraftmonitor.com/uploads/1/5/9/9/15993320/ engine_mx_concepts_for_financiers___v2.pdf.

Agrawal, V., I. Bellos. 2015. The Potential of Servicizing as a Green Business Model. Working Paper.

Agrawal, V., M. Ferguson, B. Toktay, V. Thomas. 2012. Is Leasing Greener Than Selling? Management Sci. 58(3) 523-533.

Avci, B., K. Girotra, S. Netessine. 2015. Electric Vehicles with a Switching Station: Adoption and Environmental Impact. Management Sci. 61(4) 772-794.

Bellos, I., M. Ferguson, B. Toktay. 2013. To Sell and To Provide? The Economic and Environmental Implications of the Auto Manufacturer's Involvement in the Car Sharing Business. Working Paper.

Bellos, I., S. Kavadias. 2014. A Framework for Service Design. Working Paper.

Bhavnani, R., M. Sosa. 2006. IDEO: Service Design (A\&B). INSEAD Case Study 11/20065276.

Bitner, M., A. Ostrom, F. Morgan. 2008. Service Blueprinting: A Practical Technique for Service Innovation. Calif. Manage. Rev. 50(3) 66.

Botsman, R., R. Rogers. 2011. What's Mine is Yours: How Collaborative Consumption is Changing the Way We Live. Collins.

Brown, T. 2008. Design Thinking. Harvard Bus. Rev. 86(6) 84.

Businessweek. 2014. Chinas Revised GDP Shows Rebalancing Success with Bigger Service Sector. http://www.businessweek.com/articles/2014-12-19/ china-adds-the-equivalent-of-malaysia-to-its-output.

Christensen, C., S. Cook, T. Hal. 2006. What Customers Want from your Products. Harvard Business School Newsletter: Working Knowledge . 
Corbett, C., G. DeCroix. 2001. Shared-Savings Contracts for Indirect Materials in Supply Chains: Channel Profits and Environmental Impacts. Management Sci. 47(7) 881-893.

Corbett, C., G. DeCroix, A. Ha. 2005. Optimal Shared-Savings Contracts in Supply Chains: Linear Contracts and Double Moral Hazard. Eur. J. Oper. Res. 163(3) 653-667.

Department for Environment, Food \& Rural Affairs. 2015. Digest of Waste and Resource Statistics. https://www.gov.uk/government/statistics/ digest-of-waste-and-resource-statistics-2015-edition.

European Commission. 2014. Towards a Circular Economy: A Zero Waste Programme for Europe. https://www.gov.uk/government/statistics/ digest-of-waste-and-resource-statistics-2015-edition.

Ferguson, M., E. Plambeck. 2008. Teaching note for interfaces evergreen services agreement.

Fischer, S., S. Steger, N. Jordan, M. OBrien, P. Schepelmann. 2012. Leasing Society, Policy Department A: Economic and Scientific Policy, Committee on Environment, Public Health and Food Safety, European Parliament.

Ford. 2015. Mobility Experiment: Ford Carsharing, Germany. https://media.ford.com/content/fordmedia/fna/us/en/news/2015/01/06/ mobility-experiment-ford-charsharing-germany.html.

Fortune. 2015. How Fords Chief Became a Tech CEO. http://fortune.com/2015/04/24/ mark-fields-ford-ceo/.

France24. 2013. Theft and Vandalism Blight Paris Bike-share System. http://www. france24.com/en/20130920-france-theft-vandalism-paris-bike-share-system-velib/.

Frei, F. 2005. Zipcar: Influencing Customer Behavior. Harvard Business School Case Study 9-605-054, Harvard University, Cambridge, MA.

Gebauer, H., E. Fleisch, T. Friedli. 2005. Overcoming the Service Paradox in Manufacturing Companies. European Management Journal 23(1) 14-26.

Gneezy, U., A. Rustichini. 2000. A Fine is a Price. J. Legal Stud. 291.

Greening, L., D. Greene, C. Difiglio. 2000. Energy Efficiency and Consumption-The Rebound Effect-A Survey. Energ. Policy 28(6) 389-401. 
Guajardo, J., M. Cohen, S. Kim, S. Netessine. 2012. Impact of Performance-based Contracting on Product Reliability: An Empirical Analysis. Management Sci. 58(5) 961-979.

Heiskanen, E., M. Jalas. 2000. Dematerialization Through Services: A Review and Evaluation of The Debate. Ministry of Environment.

IBM. 2014. IBM Issues Statement on U.S. Government Regulatory Approval of x86-Based Server Divestiture to Lenovo. https://www-03.ibm.com/press/us/en/pressrelease/ 44588.wss.

Kahneman, D., J. Knetsch, R. Thaler. 1991. Anomalies: The Endowment Effect, Loss Aversion, and Status Quo Bias. The Journal of Economic Perspectives 193-206.

Lambrecht, A., B. Skiera. 2006. Paying too much and Being Happy About it: Existence, Causes, and Consequences of Tariff-Choice Biases. J. Marketing Res. 43(2) 212-223.

Lenovo. 2004. Lenovo to Acquire IBM Personal Computing Division. http://www.lenovo. com/news/us/en/2005/04/ibm_lenovo.html.

Leonard, D., J. Rayport. 1997. Spark Innovation Through Empathic Design. Harvard Bus. Rev. 75 102-115.

Levitt, S., S. Dubner. 2005. Freakonomics: A Rogue Economist Explores the Hidden Side of Everything. William Morrow.

Lim, M., H. Mak, Y. Rong. 2015. Toward Mass Adoption of Electric Vehicles: Impacts of the Range and Resale Anxieties. Manufacturing Service Oper. Management 17(1) $101-119$.

MacLean, H., L. Lave. 2003. Life Cycle Assessment of Automobile/Fuel Options. Environmental science \& technology $\mathbf{3 7}(23)$ 5445-5452.

Oliva, R., J. Quinn. 2003. Interfaces Evergreen ${ }^{\mathrm{TM}}$ Services Agreement. Harvard Business School Case Study 9-603-112, Harvard University, Cambridge, MA.

Peugeot. 2015. Mu by Peugeot. http://www.peugeot.com/en/products-services/services/ mu-by-peugeot.

Rothenberg, S. 2007. Sustainability through Servicizing. Sloan Manage. Rev. 48(2) 83-91. 
Sawhney, M., S. Balasubramanian, V. Krishnan. 2003. Creating Growth With Services. MIT Sloan Manage. Rev. 45(2) 34-44.

Shostack, G. 1987. Service Positioning Through Structural Change. J. Marketing 51(1) $34-43$.

SKF. 2014. Asset Diagnostic Services. http://www.skf.com/group/services/ asset-management-services/asset-diagnostic-services/index.html.

Stahel, W. 1994. The Utilization-Focused Service Economy: Resource Efficiency and Product-Life Extension. National Academy Press, Washington. DC.

Stickdorn, M., J. Schneider. 2010. This is Service Design Thinking: Basics-Tools-Cases. BIS Publishers.

Suarez, F., M. Cusumano, S. Kahl. 2013. Services and the Business Models of Product Firms: An Empirical Analysis of the Software Industry. Management Sci. 59(2) 420-435.

Sullivan, J., E. Cobas-Flores. 2001. Full Vehicle LCAs: A Review. Tech. rep., SAE Technical Paper.

Teboul, J. 2006. Service is Front Stage: Positioning Services for Value Advantage. Palgrave Macmillan.

Thaler, R. 1980. Toward a Positive Theory of Consumer Choice. Journal of Economic Behavior \& Organization 1(1) 39-60.

The Economist. 2012. Seeing the Back of the Car. http://www.economist.com/node/ 21563280 .

The New York Times. 2009. French Ideal of Bicycle-Sharing Meets Reality. http://www. nytimes.com/2009/10/31/world/europe/31bikes.html?pagewanted=all\&_r=1\&.

The World Bank. 2013. Indicators. http://data.worldbank.org/indicator/NV.SRV.TETC. ZS.

Thomke, S. 2003. R\&D Comes to Services. Bank of Americas Path breaking Experiments. Harvard Bus. Rev. 81(4) 70-9.

Toffel, M. 2008. Contracting for Servicizing. Working Paper, Harvard Business School. 
Toktay, B., L. Selhat, R. Anderson. 2006. Doing Well by Doing Good: Interface's Vision of being the First Industrial Company in the World to Attain Sustainability. Enterprise Transformation: Understanding and Enabling Fundamental Change, W. Rouse Ed. Wiley.

Tukker, A. 2004. Eight Types of Product-Service System: Eight Ways to Sustainability? Experiences from SusProNet. Business Strategy and the Environment 13(4) 246-260.

U.S. Environmental Protection Agency. 2009. Green Servicizing for a More Sustainable US Economy: Key Concepts, Tools and Analyses to Inform Policy Engagement. http: //www.epa.gov/epawaste/conserve/tools/stewardship/docs/green-service.pdf.

U.S. Environmental Protection Agency. 2012. Municipal Solid Waste Generation, Recycling, and Disposal in the United States: Facts and Figures for 2012. http://www.epa. gov/osw/nonhaz/municipal/pubs/2012_msw_fs.pdf.

White, A., M. Stoughton, L. Feng. 1999. Servicizing: The Quiet Transition to Extended Producer Responsibility. Tech. rep., U. S. Environmental Protection Agency, Office of Solid Waste.

Wise, R., P. Baumgartner. 1999. Go Downstream. Harvard Bus. Rev. 77(5) 133-41.

Xerox. 2014. Managed Print Services. http://services.xerox.com/managed-print-services/ enus.html.

Zeithaml, V., A. Parasuraman, L. Berry. 1985. Problems and Strategies in Services Marketing. J. Marketing 49(2) 33-46. 


\section{Index}

behavioral effects, 14

normative controls, 16

endowment effect, 14

flat rate bias, 9

taxi-meter effect, 9

bike-sharing, 15

car sharing, 7, 9, 11, 15, 17, 18, 20

Car2Go, 9

chemical management solutions, 9

circular economy, 3

collaborative consumption, 16

examples

Airbnb, 16

Couchsurfing, 16

Uber, 16

commoditization, 5

coupling; see also decoupling, 3

customer journey, 18, 19

moments of truth, 19

touch-points, 19

decoupling, 9

Dell, 5

dematerialization, 9, 11, 17

design thinking, 18

disposable society, 3

waste, 3

document reproduction services, 6

empathic techniques, 18

environmental burden, 10

externalities, 15

instrumental controls, 15

floorcovering services, 14

Ford, 20

fractional ownership, 7

GM, 5

Gross Domestic Product, 4

Hewlett-Packard, 5

IBM, 5

IDEO, 19

incentives, 13

Interface, 14

Jevons paradox, 11

Lenovo, 5

lifecycle approach, 10

marketing mix, 19

mobility services, 6

NetJets, 7

order winners, 18

pay-per-use, 9, 10, 17

performance-based contracting, 8

pooling, 9, 11

Power-by-the-Hour, 8

product

efficiency, 11

reliability, 9

Product Service Systems, 6 


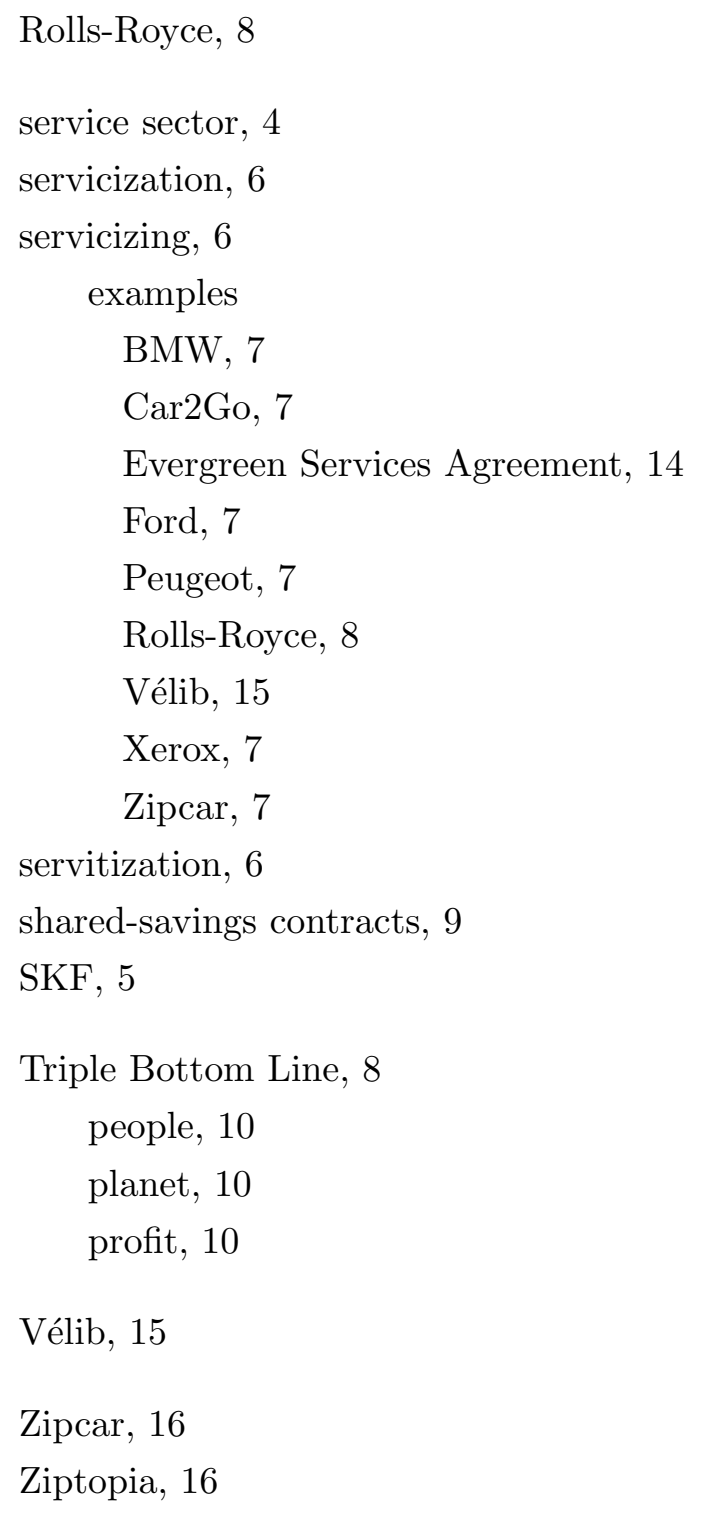

